\title{
Pengembangan Media ECHA (Elaboration, Cover Song, Historycal Content, Audio Visual) Berbasis Vlog Dalam Pembelajaran Sejarah
}

\author{
Eka Dian Susanti ${ }^{1}$, Ari Sapto ${ }^{1}$, Dewa Agung Gede Agung ${ }^{1}$ \\ ${ }^{1}$ Pendidikan Sejarah-Universitas Negeri Malang
}

\begin{tabular}{l}
\hline INFO ARTIKEL \\
\hline Riwayat Artikel: \\
Diterima: $31-10-2019$ \\
Disetujui: $12-03-2020$ \\
\hline
\end{tabular}

\section{Kata kunci:}

ECHA media; history learning;

vlog;

media ECHA;

pembelajaran sejarah;

vlog

\begin{abstract}
Vlog-based ECHA is a learning medium that was developed by adjusting the character and needs of students in sitory subjects. ECHA consists of elaboration, cover song, historycal content, and audio visual. It means that the media elaborates the song that the lyrics have changed with historycal material in the form of audio visual. ECHA media was developed with vlogs to faciltate teacher and student access that can later be used independently. The result of the trial show that this product development is pratical and can increase motivation in class XI IPS 3 SMA Negeri 1 Sumberpucung.
\end{abstract}

ABSTRAK

\begin{abstract}
Abstrak: ECHA berbasis Vlog merupakan media pembelajaran yang dikembangkan dengan menyesuaikan karakter dan kebutuhan siswa dalam mata pelajaran Sejarah. ECHA terdiri dari kata elaboration, cover song, historycal content, and audio visual. Asrtinya adalah media yang mengolaborasikan lagu yang telah diubah liriknya dengan materi Sejarah dalam bentuk audio visual. Media ECHA dikembangkan dengan Vlog untuk memudahkan akses guru maupun siswa yang nantinya juga dapat digunakan secara mandiri. Hasil dari uji coba menunjukkan bahwa produk pengembangan ini praktis dan dapat meningkatkan motivasi kelas XI IPS 3 di SMA Negeri 1 Sumberpucung.
\end{abstract}

\section{Alamat Korespondensi:}

Eka Dian Susanti

Pendidikan Sejarah

Universitas Negeri Malang

Jalan Semarang 5 Malang

E-mail: sechadian@yahoo.co.id

Pembelajaran Sejarah menjadi persoalan di sekolah karena adanya image bahwa mata pelajaran Sejarah merupakan mata pelajaran yang membosankan, kurang menarik dan dianggap hafalan (Sayono, 2013). Permasalahan tersebut tidak akan muncul apabila guru dapat melakukan improvisasi dalam pembelajaran Sejarah. Menurut (Susanto, 2014) dalam melakukan improvisasi guru dapat melakukannya melalui inovasi pembelajaran Sejarah. Inovasi dilakukan dengan mengembangkan konsep terpadu dan secara menyeluruh dengan memperhatikan tahap perencanaan, strategi, dan evaluasi dalam pembelajaran Sejarah. Perlu diberikan strategi-strategi dan teknik pembelajaran yang berbeda agar siswa lebih bersemangat dalam proses belajar, baik ketika di kelas atau secara mandiri (McCarthy \& Anderson, 2000). Selain itu, inovasi pembelajaran juga dapat dilakukan melalui media pembelajaran. Guru hendaknya dapat memilih media yang sesuai karakter siswa untuk menunjang pembelajaran yang maksimal. Media merupakan alat penyampaian pesan yang dapat digunakan dalam pembelajaran Sejarah. Media pembelajaran dapat meningkatkan motivasi belajar karena media dapat memengaruhi psikologis siswa. Media dapat digunakan untuk membangkitkan semangat dalam belajar. Media juga dapat menjadi rangsangan dalam proses belajar mengajar (Nurseto, 2012).

Guru sejarah memiliki peran penting untuk mengembangkan pendidikan yang berfokus pada kemajuan siswa. Permasalahan yang sering muncul tidak semua guru dapat mengendalikan atau mengembangkan proses pembelajaran sesuai dengan kegemaran siswa atau keinginan siswa sehingga motivasi dalam mengikuti pembelajaran rendah. Proses kegiatan belajar dan mengajar juga dipengaruhi oleh fasilitas yang tersedia di sekolah. Salah satu sekolah Negeri yang berada di Kabupaten Malang adalah SMA Negeri 1 Sumberpucung. Sekolah ini merupakan sekolah yang memiliki fasilitas yang cukup memadai dan sekolah yang memiliki banyak prestasi di bidang akademik maupun non akademik. Berdasarkan pada hasil wawancara dengan guru Sejarah Indonesia di kelas XI IPS SMA Negeri 1 Sumberpucung ditemukan permasalahan yaitu siswa kelas XI IPS III memiliki motivasi belajar yang rendah. Hal tersebut didukung dengan hasil observasi yang dilakukan peneliti bahwa kelas XI IPS III kurang memperhatikan guru pada saat pembelajaran berlangsung. Siswa secara sembunyi-sembunyi menggunakan handphone, mendengarkan musik dengan menggunakan headset dan membuka youtobe. 
Berdasarkan pada jumlah siswa yaitu 33 siswa belajar dengan audiovisual 60\%, sedangkan 20\% tipe visual dan $20 \%$ audio. Hal tersebut diamati Bapak Syamud selama mengajar di kelas. Siswa lebih menyukai belajar Sejarah dengan diberikan kebebasan mendengarkan musik. Clerk (2016) pengaruh media menjadi fitur dalam pendidikan telah merekomendasikan gambar sebagai alat yang menghemat pengajaran. Tugas belajar dengan campuran pengajaran dapat menjadi suatu alternatif. Menurut (Clark, Yates, Early, \& Moulton, 2008) media merupakan bahan aktif yang digunakan dalam pengajaran dan hal tersebut berkaitan dengan motivasi seseorang.

Media ECHA berbasis Vlog terdiri dari kata Elaboration, Cover Song, Historical Content and Audio Visual. Media ECHA merupakan media yang mengelaborasikan lagu yang telah diubah liriknya dari materi Sejarah ke dalam bentuk audio visual. Media ECHA dikembangkan berdasarkan kegemaran siswa terhadap musik dan juga untuk siswa yang belajar dengan menggunakan berbagai tipe. Media ECHA juga dipadukan dengan Vlog. Vlog sudah tidak asing lagi bagi siswa SMA Negeri 1 Sumberpucung terutama pada siswa kelas XI IPS III. Siswa seringkali mengunduh bahkan mengunggah Vlog di youtobe. Pemanfaatan Vlog dalam dunia pendidikan mulai diminati dan digunakan di dalam pembelajaran. Menurut (Sanchez-Cortes, Kumano, Otsuka, \& Gatica-Perez, 2015) Vlog dikenal dengan istilah blogging video. Blogging video saat ini populer sebagai bentuk hiburan yang akrab dengan generasi muda. Seorang vlogger yang terkenal biasanya mendapatkan viewer yang jumlahnya jutaan. Selain itu, selama ini Vlog digunakan untuk mencari kesenangan. Pengaruh youtobe yang didalamnya terdapat vlog memberikan peminatnya bertambah sehingga apabila dimanfaatkan dapat dengan mudah untuk tujuan komersial (Eun \& Watkins, 2016).

Media ECHA berbasis Vlog dikembangkan untuk meningkatkan motivasi belajar Sejarah. Motivasi belajar merupakan daya penggerak yang terdapat pada diri siswa yang dapat memunculkan proses belajar mengajar berjalan dengan baik sesuai dengan tujuan yang dikehendaki (Martínez, Santibanez, \& Mori, 2013). Motivasi belajar siswa dapat didorong salah satunya dengan pemilihan media pembelajaran yang tepat karena pada dasarnya motivasi dapat digunakan sebagai usaha dalam mencapai prestasi (Mappeasse, 2009). Peneliti mengembangkan media tersebut dengan alasan bahwa media tersebut dapat mewadai siswa yang menyukai musik akan tetapi tidak terlalu tertarik dengan pembelajaran di kelas. Media tersebut di desain untuk membuat siswa semangat dan termotivasi. Berdasarkan latar belakang tersebut maka dilakukan pengembangan dengan judul "Pengembangan Media ECHA (Elaboration, Cover Song, Historycal Content and Audiovisual) Berbasis Vlog Dalam Pembelajaran Sejarah.

\section{METODE}

Penelitian ini menggunakan penelitian pengembangan (Research and Development). Model pengembangan yang digunakan dalam penelitian ini adalah model pengembangan Lee \& Owens. Peneliti menggunakan model tersebut karena dinilai sesuai dengan pembuatan produk yang dikembangan peneliti (Wandani \& Nasution, 2017). Teknik pengumpulan data yang dilakukan oleh peneliti adalah observasi, wawancara, validasi materi, validasi media, angket dan tes. Penelitian dilakukan di SMA Negeri 1 Sumberpucung dengan subjek penelitian kelas XI IPS III. Pengembangan ini ditujukan untuk motivasi dan hasil belajar Sejarah.

\section{HASIL}

Tahap awal dalam penelitian ini ialah peneliti melakukan validasi materi. Validasi materi dilakukan untuk mendapatkan kevalidan atau kelayakan materi pada media ECHA berbasis Vlog. materi yang diuji adalah kelengkapan dan ketepatan materi. Isi materi yang terdapat pada media ECHA berbasis Vlog adalah materi respon bangsa Indonesia terhadap pendudukan Jepang. Materi terdapat pada kelas XI Sejarah Indonesia semester II. Proses validasi materi dilakukan dengan cara menyerahkan draft yang berupa materi yang didalamnya termuat skenario media yang kembangkan oleh peneliti. Validator ahli materi dalam pengembangan media ECHA berbasis Vlog adalah Dr. Joko Sayono, M.Pd. M. Hum. beliau merupakan dosen S2 Pendidikan Sejarah di Pascasarjana Universitas Negeri Malang. Berdasarkan hasil dari validasi ahli materi diperoleh bahwa kevalidan materi pada media ECHA berbasis Vlog mencapai presentase 78\%. Hasil tersebut apabila dikonversi kevalidan materi maka nilai tersebut memperoleh kualifikasi "valid". Ahli materi memberikan tanggapan bahwa materi sudah dapat digunakan untuk tahap selanjutnya.

Tahap berikutnya diakukan validasi media ECHA berbasis Vlog. Uji validasi ahli media dilakukan untuk menilai kelayakan dan kualitas media ECHA berbasis Vlog. uji coba dilakukan untuk mengetahui aspek kevalidan, kepraktisan dan keefektifan media ECHA berbasis Vlog. Ahli media pada uji validasi ini meminta bantuan Dr. Henry Praherdhiono, S. Si, M.Pd. beliau merupakan dosen S2 Teknologi Pendidikan, Fakultas Ilmu Pendidikan Universitas Negeri Malang. Proses validasi dilakukan dengan cara menyerahkan $\mathrm{CD}$ dan buku petunjuk penggunaan media ECHA karena peneliti belum melakukan pengunggahan ke dalam youtobe. Setelah uji validasi media maka akan dilakukan pengunggahan media ke dalam youtobe. Berdasarkan tabel diatas hasil dari validasi media ECHA berbasis Vlog mencapai persentase 98\%. Setelah dikonversi ke dalam tabel kevalidan menunjukkan bahwa media ECHA berbasis Vlog "sangat valid". Catatan dan saran yang ditulis oleh ahli media ialah secara teknik media layak dan valid untuk dilanjutkan pada tahap berikutnya. 
Setelah validasi materi dan media selesai maka dilakukan uji kempok keci. Uji kelompok kecil dilakukan di SMA Negeri 1 Sumberpucung pada 28 Juni 2019. Bapak Syamud selaku guru Sejarah Indonesia memberikan data siswa yang memiliki kemampuan rendah, sedang dan tinggi di kelas XI IPS IV. Uji coba kelompok kecil dilaksanakan dengan melibatkan sembilan siswa. Tujuan dari uji kelompok kecil adalah untuk mengetahui tingkat kelayakan media yang memenuhi tingkat "kepraktisan". Berdasarkan data kepraktisan uji coba kelompok kecil menunjukkan bahwa presentase media ECHA berbasis Vlog yaitu 79\%. Apabila dimasukkan ke dalam tabel kualifikasi kepraktisan maka termasuk kategori "praktis". Saran yang terdapat pada uji coba kelompok kecil yaitu terdapat tulisan yang salah ketik sehingga perlu diperbaiki. Setelah uji coba kelompok kecil maka guru Sejarah Indonesia yaitu bapak Syamud memberikan penilaian media melalui angket. Hasil dari penilaian Bapak Syamud selaku guru Sejarah memperoleh persentase sebesar 97\%. Apabila dikonversikan maka media ECHA berbasis Vlog termasuk kategori "sangat praktis" sehingga dapat digunakan sebagai media pembelajaran Sejarah. Saran dan masukan dari guru ialah agar peneliti mengembangkan lagi materi lainnya. Hal tersebut dikarenakan dengan media ECHA berbasis Vlog membuat siswa lebih mudah untuk memahami materi yang sedang dipelajari.

Tahap berikutnya dilakukan uji coba kelompok besar. Berdasarkan hasil uji coba kelompok besar maka diperoleh persentase sebesar 91\%. Apabila dimasukkan ke dalam tabel kualifikasi kepraktisan maka media ECHA berbasis Vlog memperoleh kategori "sangat praktis" sebagai media pembelajaran. Pada uji coba kelompok besar dilakukan tes hasil belajar.

Tabel 1. Analisis Data Hasil Belajar Siswa kelas XI IPS 3 (Uji Coba Kelompok Besar)

\begin{tabular}{lcc}
\hline \multicolumn{1}{c}{ Data Siswa } & Sebelum & Sesudah \\
\hline Nilai rata-rata & 57.18 & 82.42 \\
Jumlah siswa yang tuntas & 5 & 29 \\
Persentase siswa yang tuntas & $15 \%$ & $88 \%$ \\
\hline
\end{tabular}

Berdasarkan tabel 1, menunjukkan hasil prestest di kelas XI IPS III yaitu presentase siswa yang tuntas 15\%, jumlah siswa yang tuntas lima siswa dan yang tidak tuntas berjumlah 28 siswa dengan rata-rata $57.18 \%$. Nilai kriteria ketuntasan minimal SMA Negeri 1 Sumberpucung adalah 75. Berdasarkan hasil pretest dapat disimpulkan bahwa siswa kelas XI IPS III sebelum menggunakan media ECHA berbasis Vlog memiliki hasil belajar yang rendah. Setelah siswa menggunakan media ECHA berbasis Vlog didapatkan hasil evaluasi melalui postest yaitu 29 siswa tuntas dan empat siswa tidak tuntas. Rata-rata yang diperoleh 82.42 , sedangkan persentase ketuntasannya mencapai $88 \%$. Berdasarkan hal tersebut dapat disimpulkan bahwa terjadi peningkatan rata-rata siswa setelah belajar dengan menggunakan media ECHA berbasis Vlog. Dengan demikian, dapat disimpulkan bahwa pengembangan media ECHA berbasis Vlog dalam pembelajaran Sejarah dapat meningkatkan hasil belajar siswa di SMA Negeri 1 Sumberpucung.

Tabel 2. Analisis Data Motivasi Belajar Siswa kelas XI IPS III (Uji Coba Kelompok Besar)

\begin{tabular}{lcc}
\hline \multicolumn{1}{c}{ Data Siswa } & Sebelum & Sesudah \\
\hline Skor data yang diperoleh & 1349 & 2496 \\
Persentase & $50 \%$ & $94 \%$ \\
\hline
\end{tabular}

Berdasarkan tabel tersebut dapat disimpulkan bahwa motivasi belajar siswa yang tidak diberi perlakuan sebesar 50\%, apabila dikonversikan ke dalam tabel pengukuran motivasi belajar maka termasuk dalam kategori "kurang termotivasi". Akan tetapi, setelah siswa X IPS III diberi media ECHA berbasis Vlog pada pembelajaran Sejarah maka persentasenya 91\%, apabila dikonversikan maka termasuk kategori "sangat termotivasi". Berdasarkan hasil data tersebut dapat disimpulkan bahwa media ECHA berbasis Vlog dapat meningkatkan motivasi belajar Sejarah di SMA Negeri 1 Sumberpucung.

\section{PEMBAHASAN}

Sejarah merupakan mata pelajaran yang disesuaikan dengan perkembangan intelektual, spiritual, emosional, dan fisik siswa. Mata pelajaran Sejarah terkadang dipahami sebagai mata pelajaran yang sulit dan sangat membosankan. Hal tersebut dikarenakan fakta-fakta yang terdapat dalam buku teks tidak hanya untuk dipahami konsep, waktu, dan peristiwanya, tetapi juga dihafalkan (Zin, Jaafar, \& Yue, 2009). Menurut (Suryani, 2016) siswa seringkali dihadapkan pada materi Sejarah yang sifatnya abstrak sehingga dalam proses belajar mengajar sulit untuk diajarkan oleh guru dan sulit untuk dipahami siswa. Guru memiliki peranan yang penting dalam pembelajaran, salah satunya ialah memilih media pembelajaran yang tepat sesuai dengan karakteristik siswa. Media pembelajaran memiliki arti yang penting dalam proses belajar mengajar. Materi yang tidak jelas dalam peyampaiannya dapat dibantu melalui penggunaan media pembelajaran. Media dapat digunakan untuk mendukung pembelajaran sehingga materi yang bersifat abstrak dapat dikonkretkan dengan adanya media (Ainina, 2014). Berdasarkan pada permasalahan yang muncul di kelas XI IPS III SMA Negeri 1 Sumberpucung maka media pembelajaran yang tepat adalah media ECHA berbasis Vlog pada materi respons bangsa Indonesia terhadap pendudukan Jepang. 
Media ECHA berbasis Vlog terdiri dari kata elaboration, cover song, historycal content, and audio visual. Media ECHA berbasis Vlog terdiri dari kata elaboration, cover song, historycal content, and audio visual. Elaborasi merupakan pembelajaran yang disampaikan dari umum ke khusus yang diawali dengan menampilkan struktur materi yang dipelajari. Pada media yang dikembangkan diawali dengan perkenalan media, petunjuk belajar, kompetensi dasar dan indikator, materi, evaluasi, pembahasan dan penutup (Sapta, 2017). Cover song merupakan teknik yang dikembangkan peneliti untuk mengubah lirik lagu disesusaikan dengan materi yang sedang dipelajari. Menurut (Serrà, Gómez, \& Herrera, 2010) lagu menjadi sesuatu yang diminati akhir-akhir ini di dunia pendidikan. Cover song merupakan bentuk perubahan suatu lagu asli dengan kehendak seseorang yang ingin mengubah lagu tersebut. Menurut (Spalding, Klecka, Lin, Odell, \& Wang, 2010) lagu dapat dijadikan media untuk menyampaikan pesan kepada siswa dalam pembelajaran Sejarah tujuannya untuk meningkatkan motivasi siswa dalam belajar. Historical content merupakan materi Sejarah yang dikemas sesuai dengan kebutuhan siswa. Materi diambil dengan mempertimbangkan fakta baik berupa gambar atau bahan Sejarah (Leite, 2002). Menurut (Jaya, Syam, \& Seli, 2019) audio visual merupakan suatu media pembelajaran yang secara efektif dan interaktif dapat mengandung unsur suara dan gambar yang dapat menambah ketertarikan dan motivasi siswa dalam mempelajari suatu materi. Dapat disimpulkan bahwa media ECHA merupakan media yang mengelaborasikan lagu yang telah diubah liriknya kedalam materi Sejarah melalui bentuk audio visual. Audio visual memberikan paket lengkap yang melibatkan gambar dan suara yang membuat orang tertarik.

Media ECHA yang dikembangkan oleh peneliti berbasis Vlog. Vlog adalah suatu media yang digunakan untuk merekam kehidupan sehari-hari, atau berisi argumen dan berbagai pengalaman. Vlog juga dapat digunakan untuk memberikan petunjuk dalam penggunaan suatu barang atau cara mempraktikkan sesuatu (Valimbo \& Hartati, 2019). pemilihan Vlog sebagai media yang dipadukan dilatarbelakangi adanya siswa yang sudah tidak asing dengan penggunaan handphone. Perkembangan teknologi yang semakin maju ini dapat dimanfaatkan untuk hal yang baik dalam dunia pendidikan. Pembuat Vlog biasanya disebut dengan Vlogger. Tujuan dari Vlogger biasanya membuat konten yang menarik agar dapat digunakan untuk mendapatkan uang. Dalam pencariannya agar lebih mudah maka Vlog diunggah di youtobe. Vlog yang diunggah dalam youtobe lebih memudahkan banyak orang untuk mengakses. Vlog sudah menjadi gaya hidup bagi para remaja sehingga apabila Vlog digunakan dalam dunia pendidikan ini akan menjadikan hal yang positif (Harahap, 2019). Dalam penggunan Vlog dapat diakses di youtube. Youtube merupakan salah satu bentuk layanan gratis yang terdapat dalam internet untuk menikmati video-video. Vlog diunggah didalam youtube tujuannya adalah karena youtube mudah untuk mengunggah dan menyimpan video dan setelah berhasil diunduh, meskipun tidak tersambung dengan internet masih dapat dimanfaatkan. Hal tersebut memudahkan siswa apabila Vlog diunggah ke dalam youtube (Media et al., 2019). Vlog dapat dimanfaatkan dalam pembelajaran Sejarah yang efektif baik untuk guru maupun siswa karena Vlog juga salah satu bentuk dari audio visual (Susanti, 2019).

Pengembangan media ECHA berbasis Vlog dipilih sebagai alternatif media untuk kelas XI IPS III di SMA Negeri 1 Sumberpucung. Pengembangan media ini didasarkan pada karakteristik siswa. Vlog adalah suatu media yang digunakan untuk merekam kehidupan sehari-hari, atau berisi argumen dan berbagai pengalaman. Vlog juga dapat digunakan untuk memberikan petunjuk dalam penggunaan suatu barang atau cara mempraktikkan sesuatu (Valimbo \& Hartati, 2019). pemilihan Vlog sebagai media yang dipadukan dilatarbelakangi adanya siswa yang sudah tidak asing dengan penggunaan handphone. Perkembangan teknologi yang semakin maju ini dapat dimanfaatkan untuk hal yang baik dalam dunia pendidikan. Pembuat Vlog biasanya disebut dengan Vlogger. Tujuan dari Vlogger biasanya membuat konten yang menarik agar dapat digunakan untuk mendapatkan uang. Dalam pencariannya agar lebih mudah maka Vlog diunggah di youtobe. Vlog yang diunggah dalam youtobe lebih memudahkan banyak orang untuk mengakses. Vlog sudah menjadi gaya hidup bagi para remaja sehingga apabila Vlog digunakan di dalam dunia pendidikan ini akan menjadikan hal yang positif (Harahap, 2019). Dalam penggunan Vlog dapat diakses di youtube. Youtube merupakan salah satu bentuk layanan gratis yang terdapat dalam internet untuk menikmati videovideo. Vlog diunggah didalam youtube tujuannya adalah karena youtube mudah untuk mengunggah dan menyimpan video dan setelah berhasil diunduh meskipun tidak tersambung dengan internet masih dapat dimanfaatkan. Sehingga hal tersebut memudahkan siswa apabila Vlog diunggah ke dalam youtube (Media et al., 2019). Vlog dapat dimanfaatkan dalam pembelajaran Sejarah yang efektif baik untuk guru maupun siswa karena Vlog juga salah satu bentuk dari audio visual (Susanti, 2019).

Keberhasilan yang didapatkatkan dalam belajar dipengaruhi oleh pengajaran yang dilakukan guru, baik dalam pemilihan cara mengajar maupun penggunaan media yang mendukung. Peningkatan nilai menunjukkan adanya keberhasilan seorang pengajar dalam mendesain pembelajarannya (Toyiba \& Fitriyani, 2016). Keberhasilan yang didapatkan melalui media ECHA berbasis Vlog juga dapat meningkatkan motivasi XI IPS III. Uji kelompok besar menunjukkan bahwa motivasi mengalami peningkatan setelah dimanfaatkannya media ECHA berbasis Vlog ketika belajar Sejarah. Perhitungan angket motivasi belajar siswa mengalami peningkatakan yaitu 94\%. Hal itu menunjukkan bahwa siswa ingin menunjukkan kemampuannya melalui kompetensi yang telah dicapainya.

Menurut (Becker \& Gravano, 2008) ECHA berbasis Vlog ialah media yang disesuikan dengan tingka kepopulerannya di media sosial. Vlog menjadi perhatian dunia saat ini yang memiliki informasi yang menyerupai televisi (Gao, Tian, \& Huang, 2010). Vlog yang diunggah ke youtobe memberikan kemudahan kepada siswa untuk mengaksesnya. Melalui penilaian siswa maupun guru, ECHA berbasis Vlog memiliki tingkat kepraktisan, keefektifan yang praktis. ECHA berbasis Vlog mampu meningkatkan kegiatan belajar secara mandiri. Kemandirian juga didukung atas keinginan siswa yang memiliki sikap dalam memahami peranan dirinya maupun lingkungannya (Morrell \& Lederman, 1998). Musik yang terdapat pada media ECHA 
berbasis Vlog dapat mengubah cara pandang siswa terhadap materi yang sedang dipelajari. Melalui musik dapat memberikan pandangan baru tentang ilmu pengetahuannya (Cultural \& Music, 2005). Menurut (Bertin-mahieux, Ellis, Mudd, Street, \& York, 2011) lagu yang telah diubah liriknya merupakan bentuk identifikasi yang baru. Menurut (Reigeluth, 2014) lagu tersebut diubah lirik sesuai dengan materi sejarah dengan mempertimbangkan teori elaborasi. ECHA berbasis Vlog menggunakan teori elaborasi yang didasarkan tujuan dengan mengelaborasikan materi dalam bentuk lagu dapat menghasilkan pembelajaran tingkat tinggi. Hal itu dapat dilihat dengan adanya perubahan pada siswa XI IPS III SMA Negeri 1 Sumberpucung. Menunjangnya internet memberikan dampak yang baik bagi pembelajaran. ECHA berbasis Vlog memanfaatkan internet agar tidak ada batasan waktu dalam mengakses (Waldron, 2012).

\section{SIMPULAN}

Dapat disimpulkan bahwa ECHA berbasis Vlog ialah media pembelajaran Sejarah yang dikembangkan sesuai dengan kebutuhan dan karakteristik siswa yang menyukai musik. Pengembangan yang telah dilakukan menunjukkan media praktis dan valid. ECHA berbasis Vlog mampu meningkatkan motivasi XI IPS 3 SMA Negeri 1 Sumberpucung. Keunggulan dari ECHA berbasis Vlog ialah tidak ada batasan waktu dalam mengakses sehingga seteah dimanfaatkan guru, siswa dapat mengakses secara mandiri melalui youtobe. Saran ditunjukkan kepada guru agar mengembangkan media pembelajaran yang disesuaikan dengan karakteristik siswa. Media ini masih dapat dikembangkan dalam penelitian berikutnya, mengingat masih terdapat kekurangan dalam penelitian ini.

\section{DAFTAR RUJUKAN}

Ainina, I. A. (2014). Pemanfaatan Media Audio Visual sebagai Sumber Pembelajaran Sejarah. Indonesian Journal of History Education, 3(1), 40-45.

Becker, H., \& Gravano, L. (2008). Learning Similarity Metrics for Event Identification in Social Media.

Bertin-mahieux, T., Ellis, D. P. W., Mudd, S. W., Street, W., \& York, N. (2011). Large-Scale Cover Song Recognition Using Hashed Chroma Landmarks Labrosa, Columbia University. 10-13.

Clark, R., Yates, K., Early, S., \& Moulton, K. (2008). Clark, R. E., Yates, K., Early, S. \& Moulton, K. (In Press). An Analysis of the Failure of Electronic Media and Discovery-Based Learning: Evidence for the Performance Benefits of Guided Training Methods. In Silber, K. H. \& Foshay, R. (Eds.). Handbook of Training and Improving Workplace Performance, Vol. 1: Instructional Design and Training Delivery, I, 1-35.

Eun, J., \& Watkins, B. (2016). YouTube Vloggers' Influence on Consumer Luxury Brand Perceptions and Intentions. Journal of Business Research. https://doi.org/10.1016/j.jbusres.2016.04.171

Gao, W. E. N., Tian, Y., \& Huang, T. (2010). Vlogging : A Survey of Videoblogging Technology on the Web. 42(4). https://doi.org/10.1145/1749603.1749606

Harahap, S. Y. (2019). Logika (Vlog Matematika): Solusi dalam Menciptakan Generasi Cerdas dan Berbudaya. Jurnal Equation: Teori dan Penelitian Pendidikan Matematika, 2(1), 46-59. https://doi.org/10.29300/equation.v2i1.2310

Jaya, H. F., Syam, C., \& Seli, S. (2019). Peningkatan Keterampilan Menyimak Syair menggunakan Metode Discovery Learning dengan Media Audio Visual. Jurnal Pendidikan dan Pembelajaran Khatulistiwa, 8(10),1-8.

Leite, L. (2002). History of Science in Science Education: Development and Validation of a Checklist for Analysing the Historical Content of Science Textbooks. Science and Education, 11(4), 333-359. https://doi.org/10.1023/A:1016063432662

Mappeasse, M. Y. (2009). Pengaruh Cara dan Motivasi Belajar terhadap Hasil Belajar Programmable Logic Controller (PLC) Siswa Kelas III Jurusan Listrik SMK Negeri 5 Makassar. Jurnal MEDTEK, 1(2),1-6.

Martínez, J. F., Santibanez, L., \& Mori, E. E. S. (2013). Educational Opportunity and Immigration in México: Exploring the Individual and Systemic Relationships. Teachers College Record, 115(10), 11-21.

McCarthy, J. P., \& Anderson, L. (2000). Active Learning Techniques Versus Traditional Teaching Styles: Two Experiments from History and Political Science. Innovative Higher Education, 24(4), 279-294. https://doi.org/10.1023/b:ihie.0000047415.48495.05

Morrell, P. D., \& Lederman, N. G. (1998). Student's Attitudes Toward School and Classroom Science: Are They Independent Phenomena? School Science and Mathematics, 98(2), 76-83. https://doi.org/10.1111/j.1949-8594.1998.tb17396.x

Nurseto, T. (2012). Membuat Media Pembelajaran yang Menarik. Jurnal Ekonomi dan Pendidikan, 8(1), 19-35. https://doi.org/10.21831/jep.v8i1.706

Reigeluth, C. M. (2014). In Search of a Better Way to Organize Instruction : The Elabortion Theory. Journal of instructional Development, 2, 8-15. https://doi.org/10.1007/BF02984374.

Sanchez-Cortes, D., Kumano, S., Otsuka, K., \& Gatica-Perez, D. (2015). In the Mood for Vlog. ACM Transactions on Interactive Intelligent Systems, 5(2), 1-24. https://doi.org/10.1145/2641577

Sapta, A. (2017). Perbandingan Model Pembelajaran Elaborasi dengan Model Pembelajaran Advance Organizer. Keguruan: Jurnal Penelitian, Pemikiran, dan Pengabdian, 5(1), 8-13. https://doi.org/10.31227/osf.io/54gbr

Sayono, J. (2013). Pembelajaran Sejarah di Sekolah: Dari Pragmatis ke Idealis. Jurnal Sejarah dan Budaya, 7(1), $109-123$. 
Serrà, J., Gómez, E., \& Herrera, P. (2010). Audio Cover Song Identification and Similarity: Background, Approaches, Evaluation, and Beyond. Studies in Computational Intelligence, 274, 307-332. https://doi.org/10.1007/978-3-642-11674$2 \_14$

Spalding, E., Klecka, C. L., Lin, E., Odell, S. J., \& Wang, J. (2010). Social Justice and Teacher Education: A Hammer, a Bell, and a Song. Journal of Teacher Education, 61(3), 191-196. https://doi.org/10.1177/0022487109359762

Suryani, N. (2016). Pengembangan Media Pembelajaran Sejarah Berbasis IT. Sejarah dan Budaya: Jurnal Sejarah, Budaya, dan Pengajarannya, 10(2), 186-196. https://doi.org/10.17977/um020v10i22016p186

Susanti, E. D. (2019). Project Based Learning: Pemanfaatan Vlog Dalam Pembelajaran Sejarah untuk Generasi Pro Gadget. Sejarah dan Budaya: Jurnal Sejarah Budaya dan Pengajarannya, 13(1), 84-96. https://doi.org/10.17977/um020v13i12019p084

Valimbo, I. A., \& Hartati, E. (2019). Vlog To Improve Students Speaking Skill : A Classroom Action Research. Prosiding Konferensi Pendidikan Nasional "Penguatan Karakter Bangsa Melalui Inovasi Pendidikan di Era Digital” 91-97.

Waldron, J. (2012). YouTube, Fanvids, Forums, Vlogs, and Blogs: Informal Music Learning in A Convergent on-and Offline Music Community. International Journal of Music Education, 31(1), 91-105. https://doi.org/10.1177/0255761411434861

Wandani, N. M., \& Nasution, S. H. (2017). Pengembangan Multimedia Interaktif dengan Autoplay Media Studio pada Materi Kedudukan Relatif Dua Lingkaran. Jurnal Kajian Pembelajaran Matematika, 1(2), 90-95.

Zin, N. A. M., Jaafar, A., \& Yue, W. S. (2009). Digital Game-Based Learning (DGBL) Model and Development Methodology for Teaching History. WSEAS Transactions on Computers, 8(2), 322-333. 